Revista de Educação e Pesquisa em Contabilidade

Journal of Education and Research in Accounting

Revista de Educación e Investigatión en Contabilidad
REPeC, Brasília, v. 6, n. 2, art. 2, p. 141-153, abr./jun. 2012 Disponível online em www.repec.org.br

ISSN 1981-8610

\title{
Implicações de Crises Econômicas na Relevância da Informação Contábil das Empresas Brasileiras
}

\author{
Fábio Moraes da Costa \\ Doutor em Controladoria e Contabilidade (FEA-USP) \\ Professor Associado da Fucape Business School \\ Endereço: Av. Fernando Ferrari, 1358, Boa Vista-Vitória (ES) / CEP: 29055-290 \\ E-mail:fabio@fucape.br
}

\section{Danilo José Santana dos Reis}

Mestre em Ciências Contábeis na FUCAPE Business School

Economista do Banco do Nordeste do Brasil S. A.

Endereço: Rua Marquês de Paranaguá, 280, Centro - Ilhéus (BA) / CEP: 45.653-000

E-mail: daniloreis@bnb.gov.br

\section{Arilda Magna Campagnaro Teixeira}

Doutora em Economia pelo IE-UFRJ

Professora Assistente da Fucape Business School

Endereço: Av. Fernando Ferrari, 1358 Boa Vista - Vitória (ES) / CEP: 29.075-505

E-mail: arildat@fucape.br

\section{Resumo}

Este estudo examina se em períodos de crises financeiras no Brasil (1997-1999, 2002 e 2007-2008) a relevância da informação contábil sofre impacto, tanto em relação ao patrimônio líquido quanto ao resultado. Para tanto, a amostra foi composta por 1.904 observações, entre 1997 e 2010. Trata-se de um estudo empírico que se utiliza de análise de regressão com dados em painel. Para responder à questão de pesquisa foi utilizada uma regressão empregando-se uma variável dummy para os anos de choques macroeconômicos negativos e como estes afetam a relação entre os preços de mercado e as variáveis contábeis. Os resultados indicam que as crises afetam, positivamente, a relevância do patrimônio líquido e, negativamente, a do lucro líquido, corroborando estudos realizados anteriormente na Tailândia e no México. Assim, os efeitos macroeconômicos devem ser levados em consideração nas análises de como a informação contábil captura a realidade econômica das empresas. Sugere-se, para as próximas pesquisas, que seja analisada uma amostra de países latino-americanos para avaliar se há similaridade nos efeitos da relevância da informação contábil ou se as políticas estabelecidas para mitigar os efeitos da crise podem levar a impactos diferenciados.

Palavras-chave: Crises; Relevância da Informação Contábil; Modelo de Ohlson.

\section{Editado em Português, Inglês e Espanhol. Versão original em Português.}

Recebido em 30/12/11. Pedido de Revisão em 01/02/12. Resubmetido em 26/03/12. Aceito em 27/03/2012 por Valcemiro Nossa (Editor). Publicado em 28/06/12. Organização responsável pelo periódico: CFC/FBC/ABRACICON.

Copyright (C 2012 REPEC. Todos os direitos, até mesmo de tradução, são reservados. É permitido citar parte de artigos sem autorização prévia, desde que seja identificada a fonte. 


\section{INTRODUÇÃO}

O efeito da propagação da crise iniciada em 2007 nos Estados Unidos e relacionada ao mercado imobiliário acabou por gerar demanda por trabalhos que auxiliem na interpretação e melhor entendimento de seus efeitos no mercado financeiro. Assim, o presente estudo tem como objetivo avaliar se a relevância da informação contábil é afetada em períodos de crises macroeconômicas.

As informações contábeis divulgadas possuem o objetivo de reduzir a assimetria informacional e auxiliar no monitoramento de contratos (LOPES e MARTINS: 2005). Assim, a mesma é entendida como relevante quando auxilia usuários do mercado em suas predições e, consequentemente, possui relação com os preços das ações.

Empiricamente, o constructo "relevância" foi usualmente testado por meio da associação de variáveis de mercado, principalmente após o desenvolvimento do modelo de Ohlson (1995). O arcabouço conceitual (conceptual framework) do International Accounting Standards Board e que foi adotado no Brasil tem a relevância como uma característica qualitativa fundamental da informação contábil.

Os modelos de avaliação de preço de ativos foram usados amplamente nos estudos da Contabilidade para examinar a relevância da informação (COLLINS, PINCUS e XIE, 1999). Geralmente, os estudos de value relevance mensuram, especificamente, um modelo explícito de avaliação, envolvendo regressões que têm como variável dependente o valor de mercado da ação e como variável explicativa o resultado contábil (HOLTHAUSEN e WATTS, 2001).

De forma geral, os trabalhos trazem evidências de que a informação contábil é relevante, possibilitando avaliá-la de maneira agregada (FELTHAM e OHLSON: 1995; MYERS: 1999; OHLSON e JUETTNER-NAROUTH, 2005) ou para itens específicos, tais como aspectos ligados a ajustes decorrentes da inflação (DYCKMAN: 1975) ou ativos intangíveis (AMIR e LEV, 1996).

No Brasil, Lopes (2001) foi o primeiro a aplicar o modelo de Ohlson (1995) em companhias listadas na Bolsa de Valores de São Paulo (Bovespa) e verificou que as informações do patrimônio líquido e do lucro líquido são relevantes para explicar os preços das ações. Os resultados mostraram que o modelo de avaliação (OHLSON, 1995) baseado em números contábeis superou o tradicional modelo dos dividendos descontados em muitos períodos analisados.

Outras pesquisas relacionadas à relevância da informação foram desenvolvidas em condições especiais de mercado: no estudo de Basu (1997), focado na existência do conservadorismo condicional, o autor apresentou resultados que reforçam a relevância da informação contábil para o mercado de capitais, chegando à conclusão de que as "más notícias" são reconhecidas mais rapidamente do que as "boas notícias" no resultado.

Diferenças no ambiente institucional dos países, no regime contábil e na estrutura de governança corporativa, são temas que atualmente vêm sendo pesquisados e associados à relevância da informação contábil. As evidências apontam que em mercados de capitais desenvolvidos, com controle acionário descentralizado e com melhores práticas de governança, os números contábeis tendem a ser mais relevantes para os investidores (LOPES e WALKER: 2012).

Porém, no contexto internacional, a maior parte dos trabalhos está baseada em dados de países desenvolvidos, principalmente norte-americanos, ingleses, australianos e canadenses (MEEK e THOMAS, 2004). Assim, pesquisas sobre a relevância da informação contábil que considerem aspectos específicos, principalmente de países emergentes, ainda constituem um campo profícuo para a geração de novas evidências. Nesse sentido, um item recorrente na realidade de uma série de nações em desenvolvimento consiste em sua vulnerabilidade a crises macroeconômicas, fato que pode ser corroborado pela instabilidade dos últimos quinze anos: México, Coreia do Sul, Indonésia, Malásia, Tailândia, Rússia, Brasil e Argentina.

Dado que usualmente trabalhos científicos mensuram o grau de associação entre variáveis contábeis e de mercado, é possível questionar se as crises macroeconômicas podem afetar a relevância da informação contábil (GRAHAM e KING: 2000).

Pesquisas desenvolvidas em países asiáticos e no México (GRAHAM e KING, 2000; HO et al., 2001; DAVIS-FRIDAY et al., 2006; DAVIS-FRIDAY e GORDON, 2005) têm demonstrado que, em 
períodos de crise econômica, há evidência de que o valor informacional da contabilidade é afetado. Uma evidência importante revelada nas citadas pesquisas é que, geralmente, em países que possuem a contabilidade baseada no regime jurídico code-law ${ }^{1}$, em períodos de crise, a relevância do patrimônio líquido tem aumentado enquanto a relevância do lucro tem diminuído. O Brasil, pelas suas características de alta regulamentação, é considerado um país de regime jurídico code-law (COSTA, LOPES e COSTA: 2006). Porém, nos últimos anos, as alterações de modelo contábil (Lei n. ${ }^{\circ}$ 11.638/2007 e os pronunciamentos emitidos pelo International Accounting Standards Board) e também de tributação (Lei n. ${ }^{0}$ 11.941/2009) consistiram na implementação de uma filosofia mais próxima da de países common-law.

Este estudo considerou que os anos 1997, 1998, 1999, 2002, 2007 e 2008 foram de crise da economia brasileira. Os anos de 1997 e 1998 foram reflexos de crises externas (Ásia e Rússia); 1999 e 2002 estiveram relacionadas com a desvalorização do real em relação ao dólar; 2007 e 2008 estão relacionados aos efeitos da crise do subprime norte-americano à queda acentuada da Bolsa de Valores brasileira. Em todos os referidos anos, ocorreram distorções macroeconômicas que desencadearam ações do Governo e do Banco Central para estabilizar a economia.

Diante dos resultados de Lopes (2001) e Costa (2005), demonstrando a utilidade das informações emanadas pela Contabilidade para o mercado de capitais no Brasil, e das evidências de estudos internacionais de que a relevância da informação contábil sofre alteração em períodos de crise, o presente estudo investiga se as crises macroeconômicas afetam a relevância da informação contábil de companhias listadas brasileiras. O objetivo é investigar se há impacto em como as informações contábeis capturam a realidade econômica de uma determinada empresa.

Os resultados confirmam que as crises impactaram a relevância da informação contábil no Brasil de forma diferenciada: houve aumento da relevância do patrimônio líquido e redução da relevância do lucro líquido. Assim, a pesquisa contribui para a compreensão de como fatores macroeconômicos afetam a relação entre a informação contábil e os preços de mercado.

\section{REVISÃO DA LITERATURA}

Economistas como Smith, Say, David Ricardo, Malthus e Marshall referiram-se ou utilizaram dados contábeis para validar seus estudos. O uso de informações contábeis para validar a Teoria da Firma foi um ganho teórico primário da relação existente entre Microeconomia e Contabilidade (YU, 1966, p. 11).

Enquanto a Microeconomia estuda a empresa em uma perspectiva individual, analisando a sua atuação em mercados privados por meio do ponto de equilíbrio entre preço e quantidades, a Macroeconomia analisa a Economia como um todo. O agregado macroeconômico é composto da soma de todas as atividades individuais do mercado.

Em termos macroeconômicos, o nível e a trajetória da taxa de juros, bem como as variações cambiais, influenciam as ações de indivíduos e firmas. Medidas de política monetária têm o poder de influenciar as decisões de poupança dos indivíduos e de investimento das firmas (ARAÚJO e GUILLÉN, 2002). Assim, uma empresa que decide investir utilizando capital de terceiros de origem estrangeira está suscetível a ganhos ou perdas por variação cambial, que refletirão nas suas demonstrações contábeis.

A Macroeconomia trata de agregados ou insumos e produtos totais, enquanto a Contabilidade estuda a composição dos mesmos. De forma genérica, considera-se que a Macroeconomia estuda dados consolidados das transações econômicas realizadas individualmente em toda Economia.

Um aspecto importante da relação entre Economia e Contabilidade é a oportunidade (Timeliness) da informação criada pela Contabilidade. A contabilidade é oportuna quando reflete a realidade econômica mais rapidamente. A informação contábil precisa refletir a realidade econômica ou os usuários não a utilizarão, perdendo assim a sua razão de ser (LOPES e MARTINS, 2005, p. 61).

\footnotetext{
1 Países com estruturas gerais de organização mais regulamentadas, com forte interferência da legislação tributária na Contabilidade, com estrutura acionária das empresas concentrada nas mãos de poucos acionistas que normalmente são os gestores.
} 
Ball, Kothari e Robim (2000) analisaram a oportunidade do resultado contábil entre países de modelo code-law e commom-law, estabelecendo a relação entre resultado contábil (variável dependente) e resultado econômico (variável independente). Estes observaram que o poder explicativo da regressão é mais oportuno em países commom-law. Em países common-law, o lucro contábil reconhece efetivamente o resultado econômico com alto poder explicativo, o que não ocorre nos países code-law.

\subsection{Relevância da informação contábil}

Pesquisas acadêmicas com foco em value relevance usualmente adotam a perspectiva do investidor. Este grupo seria o primeiro interessado na informação que pode ajudá-lo a avaliar empresas para finalidades de fazer escolhas e tomar decisões (BARTH, 2000, p. 10). Essencialmente, os estudos de value relevance implicam o papel da Contabilidade de fornecer estimativas de valores de mercado da ação ou suas transformações lineares (HOLTHAUSEN e WATTS, 2001).

Os trabalhos desenvolvidos por Ohlson (1995), Feltham e Ohlson (1995), Myers (1999), Lopes (2001) e Ohlson e Juettner-Nauroth (2005) continuaram testando o poder da informação contábil sobre os preços do mercado de capitais.

Barth, Beaver e Landsman (2001) consideram o modelo de Ohlson (1995) e suas atualizações amplamente difundidos e aceitos nos estudos acerca da relevância de variáveis contábeis. Geralmente, os estudos de value relevance mensuram especificamente um modelo explícito de avaliação. Tais estudos envolvem regressões do valor de mercado da ação e lucros, sendo a expectativa de lucro futuro descontada por uma taxa estimada (HOLTHAUSEN e WATTS, 2001).

Barth, Beaver e Landsman (2001), analisando pesquisas sobre value relevance, concluíram que várias estimativas de valor justo de ativos e passivos de fundos de pensão, valor justo de títulos de dívida, empréstimos bancários, derivativos, ativos não financeiros intangíveis e tangíveis de longa duração são valores relevantes.

Os modelos de avaliação de preço de ativos foram usados extensivamente na pesquisa da Contabilidade para examinar a relevância do valor da informação contábil (COLLINS, PINCUS e XIE, 1999). No Brasil, Lopes (2001) utilizou o modelo de Ohlson (1995) em empresas com ações listadas na Bovespa. Os resultados demonstraram-se satisfatórios, entretanto, verificou-se que o poder explicativo do modelo está concentrado no patrimônio líquido e, não, nos lucros anormais futuros. Tais resultados foram corroborados pelos achados de Costa (2005), com foco na comparação entre o conteúdo informacional das informações, conforme o modelo brasileiro e norte-americano das companhias brasileiras com ADRs negociados na Bolsa de Nova Iorque.

Após revisão geral do assunto, Lopes (2001, p. 90) conclui que “o resultado contábil é relevante, mas possui baixo poder explicativo". O autor afirma que "relevância dos resultados contábeis também depende de condições gerais de funcionamento do mercado e do nível de eficiência do mesmo" (LOPES, 2001, p. 90). Hendriksen e Breda (1999, p. 206) afirmam existir uma correlação imperfeita entre lucro e preço, devido ao "fato de que os preços captam o impacto de um conjunto de informações muito mais amplo do que o representado apenas por lucros contábeis" e pelo fato de que algumas variações dos lucros contábeis resultam de mudanças de normas contábeis, sem qualquer implicação econômica imediata.

Ohlson (1995) mostra que, assumindo o clean surplus relation (CSR) e uma informação linear dinâmica específica, o preço pode ser representado como uma função linear do lucro e do patrimônio líquido.

The Ohlson (1995) model suggests that book value of equity reflects the present value of expected future normal earnings since a firm can be expected to generate a return on its net assets that equals its expected cost of equity capital (COLLINS, PINCUS E XIE, 1999).

\subsubsection{Relevância da informação contábil e crises econômicas}

A associação entre crises econômicas e poder explicativo da informação contábil foi objeto de estudo de Graham e King (2000), Ho et al. (2001), Davis-Friday et al. (2006) e Davis-Friday e Gordon 
(2005). Esses estudos sugerem que os países podem ser afetados diferentemente por uma crise econômica resultante de problemas no mercado monetário (desvalorização da moeda doméstica) e no mercado de capitais (declínio do preço das ações).

Graham e King (2000) verificaram que, no ano 1997 na Tailândia, com a desvalorização do Thai Baht, houve um declínio na relevância do lucro, enquanto a do patrimônio líquido aumentou. A desvalorização foi acompanhada de elevada volatilidade da taxa de câmbio. A mudança na relevância do valor da informação da Contabilidade depois da desvalorização pode ser atribuída ao reconhecimento inicial de perdas da variação cambial e ao reconhecimento subsequente de ganhos de variação cambial, quando a taxa de câmbio caiu e em seguida se recuperou.

Na Coreia, Ho et al. (2001) apud Davis-Friday e Gordon (2005), os resultados indicaram que a relevância do valor do lucro contábil declinou significativamente da pré-crise (1995-1996) aos períodos da crise (1997-1998). No entanto, essa diminuição do lucro não foi substituída por um aumento significativo do valor patrimônio líquido.

A crise monetária do México, de 1994, foi objeto de estudo de Davis-Friday e Gordon (2005), os quais analisaram a relação entre os preços das ações das empresas e seus valores contábeis, lucro e fluxos de caixa. Os resultados demonstraram que a relevância no valor do patrimônio líquido não mudou significativamente durante o período da crise, enquanto o seu poder explicativo incremental aumentou. Quanto ao lucro, houve um declínio significativo na sua relevância e no seu poder explicativo durante a crise.

Davis-Friday et al. (2006) analisaram a relevância do lucro e patrimônio líquido em quatro países do Continente Asiático (Coreia, do Sul, Indonésia, Malásia e Tailândia), na crise de 1997, encontrando evidências de que geralmente, em períodos de crise, a relevância informacional do lucro diminui e do patrimônio líquido aumenta dependendo dos mecanismos de governança corporativa e do sistema de contabilidade do país. Países que possuem a contabilidade baseada no regime jurídico code-law, em períodos de crise, sofrem aumento na relevância do patrimônio líquido enquanto a relevância do lucro diminui.

\subsection{A crise asiática e a crise russa: efeito contágio}

A ocorrência de crises cambiais e ataques especulativos simultâneos ou sequenciais em diversos países que demonstravam alguma relação com os números da economia brasileira foram intitulados por diversos autores como efeito contágio.

Para Gremaud, Vasconcelos e Toneto Júnior (2004), o efeito contágio ocorreu no período de 1997 a 1998, nas crises asiática e russa, e teve como consequência imediata o aumento da dívida pública e a ampliação da taxa de juros.

A economia brasileira no ano de 1997 apresentou uma fuga de dólares de, aproximadamente, US\$ 20 bilhões. A economia reagiu ao pacote fiscal e ao aumento da taxa de juros, e as reservas foram restabelecidas. Mas, em 1998, houve uma perda de reservas de, aproximadamente, US\$ 30 bilhões entre os meses de agosto e setembro que, apesar do aumento dos juros e do pacote fiscal, não houve recuperação. Para sanar a fuga de reservas, o Brasil negociou um acordo com o Fundo Monetário Internacional (FMI) no valor de US\$ 42 bilhões (LANZANA, 2001).

O desempenho da economia brasileira nos anos de 1997 e 1998 evidenciou que a economia brasileira está suscetível a choques macroeconômicos gerados por outros países.

Outro ponto relevante é que as crises externas podem ter reflexo em períodos futuros. Baer (2002, p. 237) afirma que a crise da Ásia e a crise da Rússia levaram o Plano Real a um ponto crítico em 1999. Nesse estudo, foram considerados os anos de 1997 e 1998 como anos de crise devido ao efeito contágio observado.

\subsection{O Brasil e as crises financeiras de 1999 e 2002}

O Plano Real apresentou uma inovação significativa na política de estabilização, na medida em que pôde utilizar novos instrumentos macroeconômicos que não estavam disponíveis nos planos anteriores. Desde o Plano Cruzado, os elementos utilizados para interromper a aceleração inflacionária foram: 
reformas monetárias, desindexação dos contratos, congelamento de preços e sequestro de ativos financeiros. O Plano Real representa um divisor de águas com relação a estes procedimentos na medida em que passa a utilizar o câmbio e os juros como instrumentos chaves para a estabilização.

Anteriormente à mudança no regime cambial, todo movimento mais significativo de saída de capitais de curto prazo se refletia em uma perda de reservas por parte do Banco Central do Brasil (BCB), ameaçando a manutenção do regime de câmbio semifixo, o que obrigava o $\mathrm{BCB}$ a elevar a taxa de juros doméstica de forma a induzir uma reversão do movimento de saída de capitais. Após a mudança do regime cambial, os movimentos de saída de capitais passaram a se refletir também sobre a taxa de câmbio, cuja desvalorização passaria a colocar em risco a estabilidade da taxa de inflação. Gremaud, Vasconcelos e Toneto Júnior (2004, p.489) demonstraram que a desvalorização da taxa de câmbio em janeiro de 1999 foi em torno de $65 \%$ e que, apenas neste mês, o aumento da dívida pública, para o Tesouro Nacional, foi de, aproximadamente, $\mathrm{R} \$ 50$ bilhões.

Dessa forma, o Governo e o BCB foram obrigados a adotar medidas restritivas que acompanharam a desvalorização: na área fiscal ocorreu redução de gastos públicos e aumento de tributos e, na área monetária, forte elevação das taxas de juros, que chegaram a 42\% ao ano no início de 1999 (LANZANA, 2001). A elevação, por diversas vezes, da taxa de juros no intuito de reverter o fluxo de saída de capitais e impedir o aumento da inflação, afetou tanto o crescimento econômico quanto o volume da dívida pública.

Cardoso e Helwege (1999), Miranda (1999), Murta et al. (2003) observaram que a causa principal da crise brasileira de 1999 está associada à deterioração dos fundamentos econômicos, em particular a apreciação cambial, os déficits em transações correntes e o aumento da dívida pública em nível bastante elevado.

As mudanças que ocorreram a partir de 1999 procuraram alterar a trajetória da economia e recuperar a capacidade de financiamento externo e do governo. As três grandes alterações de política econômica que passaram a condicionar os cenários futuros da economia brasileira foram: programa de ajuste fiscal, modificação do regime cambial e programa de metas inflacionárias.

O programa de ajuste fiscal, destinado a reverter a trajetória explosiva do déficit e da dívida pública interna, foi um dos programas mais ambiciosos de redução de déficit fiscal já acordado com o FMI por países com crise de balanço de pagamentos, envolvendo um ajuste físcal da ordem de $4 \%$ do PIB. O programa de metas inflacionárias, inaugurado em meados de 1999, após a mudança do regime cambial, onde o poder discricionário do Banco Central passou a ser direcionado para coordenar as expectativas dos agentes econômicos através de metas inflacionárias declinantes, conseguiu manter a inflação dentro dos limites da meta somente nos dois primeiros anos. A partir de 2002, a inflação ultrapassou o limite superior da meta, colocando em cheque a credibilidade do programa.

$\mathrm{O}$ ano de 2002 foi marcado pela vulnerabilidade externa do país e pela fragilidade financeira do setor público. A desvalorização da taxa de câmbio e a elevada fuga de dólares levaram o Governo a adotar, mais uma vez, medidas restritivas, como redução de gastos públicos e aumento de tributos; e na área monetária, o Banco Central elevou as taxas de juros. Tais medidas foram utilizadas para inibir o aumento da inflação. Por esses motivos, a economia brasileira apresentou baixo desempenho.

Apesar disso, o ano de 2002 foi marcado pelo aumento das exportações, favorecidas pela desvalorização do Real e decréscimo das importações. "O superávit comercial atingiu US\$ 13,1 bilhões (crescimento de mais de 400\%), propiciando o maior saldo conseguido desde 1993” (FILGUEIRAS, 2003, p. 241).

\subsection{A crise do subprime}

A queda dos preços dos imóveis nos Estados Unidos desencadeou um efeito dominó no mercado financeiro e, posteriormente, na economia real. As operações com derivativos e a falência de grandes bancos de investimento levou a um efeito de restrição de crédito e impactou negativamente todas as principais economias mundiais (CROUHY, JARROW e TURNBULL: 2008). O efeito chegou ao Brasil ainda em 2007: o Ibovespa encontrava-se acima de 60.000 pontos e chegou a ficar abaixo de 30.000 pontos. $O$ Governo brasileiro teve que estabelecer uma série de políticas para evitar, como, por exemplo, alterações de taxas de juros e também dos tributos. Apenas em 2009, o principal índice da BM\&FBovespa retornou a patamares próximos do período anterior à crise. 


\section{DESENVOLVIMENTO DA HIPÓTESE DE PESQUISA}

As evidências apresentadas por Barth et al. (1998), Davis-Friday e Gordon (2005) e Davis-Friday et al. (2006) indicam que, em períodos de crise, há impacto na relevância do lucro e do patrimônio líquido. Além disso, Davis-Friday, Eng e Liu (2006) argumentam que o impacto na relevância das variáveis contábeis pode ser diferenciado: a relevância do patrimônio líquido aumentaria, por ser uma proxy do valor de liquidação das empresa. Por outro lado, o resultado contábil tornar-se-ia menos relevante, pois a instabilidade poderia afetar sua utilização para projeção de resultados futuros (DAVIS-FRIDAY, ENG e LIU: 2006). Assim, a seguinte hipótese será testada neste estudo:

H1. Crises econômicas afetam a relevância do patrimônio líquido e do lucro líquido das companhias abertas brasileiras.

\section{METODOLOGIA}

Para responder à questão de pesquisa, foi utilizada uma regressão que avaliou se os choques macroeconômicos dos anos de crise (1997, 1998, 1999, 2002, 2007 e 2008) afetaram o valor informacional contábil das empresas brasileiras. Adicionalmente, também foi avaliado se a relevância do valor informacional do patrimônio líquido das empresas brasileiras aumentou enquanto a do lucro diminuiu com o referido choque.

A metodologia adotada neste estudo é similar à adotada nos estudos de Barth (1998) e Davis-Friday et al. (2006) para examinar a relevância do patrimônio líquido e do lucro, ambos baseados no modelo de Ohlson (1995). O valor de mercado da ação é a variável dependente do modelo, enquanto lucro e patrimônio líquido são as variáveis explicativas. O modelo inclui uma variável dummy para examinar o efeito da crise na relevância do lucro e do patrimônio líquido.

O modelo de Ohlson (1995) considera que o "valor de mercado de uma empresa é função do lucro e do valor do patrimônio líquido" (CARDOSO e MARTINS, 2004). Conforme o modelo, o valor da empresa pode ser representado pela equação 1 . A equação 1 foi testada neste estudo no intuito de verificar o poder explicativo das variáveis contábeis patrimônio líquido e lucro líquido para o mercado brasileiro. Todas as variáveis são divididas pelo valor de mercado da empresa do ano anterior.

$$
\mathrm{VM}_{\text {it }}=\beta_{0}+\beta_{1} \mathrm{PL}_{\mathrm{it}}+\beta_{2} \mathrm{LUC}_{\mathrm{it}}+\varepsilon_{\mathrm{it}}
$$

\section{Onde:}

$\mathrm{VM}_{\mathrm{ij}}=$ Valor de mercado da empresa i, após o encerramento do exercício t;

$\mathrm{PL}_{\mathrm{ij}}=$ Patrimônio líquido da empresa i no ano $\mathrm{t}$;

$\mathrm{LUC}_{\mathrm{ij}}=$ Lucro líquido da empresa i no ano t;

$\varepsilon_{\mathrm{ij}}=$ outras informações relevantes.

A equação 2, testada neste estudo, tem como variável dependente o valor de mercado da ação em abril do ano $\mathrm{t}$ (dividido pelo valor de mercado do ano t-1) e duas variáveis explicativas: valor contábil da ação e lucro por ação (divididos pelo valor de mercado do ano t-1). Além disso, visando dar maior robustez aos resultados, os dados serão rodados em painel com duplo efeito fixo (por companhia e por ano). Assim, a seguinte equação foi utilizada neste estudo:

$$
\mathrm{VM}_{\mathrm{it}}=\beta_{0}+\beta_{\mathrm{i}}+\beta_{\mathrm{j}}+\beta_{1} \mathrm{CR}_{\mathrm{i}}+\beta_{2} \mathrm{PL}_{\mathrm{it}}+\beta_{3} \mathrm{CR} \times \mathrm{PL}_{\mathrm{it}}+\beta_{4} \mathrm{LUC}_{\mathrm{it}}+\beta_{5} \mathrm{CR} \times \mathrm{LUC}_{\mathrm{it}}+\varepsilon_{\mathrm{it}}
$$

\section{Onde:}

$\mathrm{CR}_{\mathrm{i}}=$ variável dummy, que assume 0 para o período sem crise, e 1, para os anos de crise: 1997, 1998, 1999, 2002 e 2008; 
$\mathrm{VM}_{\mathrm{ij}}=$ Valor de mercado da empresa i em 30 de abril no ano $\mathrm{t}+1$;

$\mathrm{PL}_{\mathrm{ij}}=$ Patrimônio líquido da empresa i no ano t;

$\mathrm{LUC}_{\mathrm{ij}}=$ Lucro líquido da empresa i no ano t;

$\varepsilon_{\mathrm{ij}}=$ Termo de erro da regressão.

Com base na literatura apresentada anteriormente, são esperados os seguintes resultados: o sinal de $\beta_{1}$ seja negativo, demonstrando o efeito negativo da crise sobre o valor de mercado; os sinais de $\beta_{2}$ e $\beta_{4}$ sejam positivos, conforme prevê o modelo de Ohlson (1995); o sinal de $\beta_{3}$ positivo, demonstrando que o PL em períodos de crise tem relevância; e o sinal do $\beta_{5}$ seja negativo.

\subsection{Amostra}

Esta pesquisa foi desenvolvida com dados anuais das companhias listadas na BM\&FBovespa, compreendendo o período entre 1997 a 2010. Os dados foram coletados no banco de dados Economática.

Inicialmente, foram selecionados os valores de mercado da empresa no dia 30 de abril de cada ano, dado que as demonstrações financeiras podem ser publicadas até o dia 30 de abril do ano subsequente. Esta especificação tem como objetivo evitar períodos nos quais mais de uma demonstração financeira anual tenha sido publicada e estar em linha com pesquisas anteriores (COSTA: 2005, por exemplo). Os dados do patrimônio líquido e do lucro foram coletados dos balanços consolidados do mês de dezembro de cada ano.

A regressão da Equação 2 será rodada em painel, com efeito fixo para as companhias (cross-section). O objetivo é controlar por características específicas de cada empresa. Não foi utilizado o efeito fixo para a variável "ano", com a finalidade de se evitarem problemas de especificação pela inserção da variável CR (dummy para os anos de crise).

Para tratar o efeito de outliers, foi aplicada a técnica "winsor" para $1 \%$ em cada cauda da distribuição. As estatísticas descritivas das três principais variáveis utilizadas neste estudo são apresentadas a seguir:

Tabela 1: Estatísticas Descritivas (1996 a 2005)

\begin{tabular}{|c|c|c|c|c|c|c|c|c|c|c|c|c|c|c|c|}
\hline \multirow{2}{*}{ Ano } & \multicolumn{5}{|c|}{ LUC } & \multicolumn{5}{|c|}{ PL } & \multicolumn{5}{|c|}{ VM } \\
\hline & Obs. & Média & DP & Min. & Máx. & Obs. & Média & DP & Min. & Máx. & Obs. & Média & DP & Min. & Máx. \\
\hline 1997 & 223 & 75 & 412 & (402) & 3.900 & 223 & 1.051 & 4.967 & (338) & 61.600 & 272 & 988 & 3.638 & 0,16 & 39.100 \\
\hline 1998 & 261 & 44 & 289 & $(2.860)$ & 1.994 & 262 & 951 & 4.175 & $(2.635)$ & 60.000 & 282 & 570 & 1.437 & 0,15 & 11.400 \\
\hline 1999 & 273 & 41 & 245 & (535) & 1.869 & 273 & 1.032 & 4.115 & (281) & 59.400 & 322 & 1.183 & 3.713 & 0,11 & 46.200 \\
\hline 2000 & 273 & 121 & 689 & $(2.085)$ & 9.942 & 273 & 1.117 & 4.374 & $(1.342)$ & 62.100 & 295 & 1.326 & 4.164 & 0,51 & 51.400 \\
\hline 2001 & 277 & 127 & 711 & (1.113) & 9.867 & 277 & 1.206 & 4.572 & $(1.575)$ & 64.300 & 290 & 1.349 & 4.394 & 0,15 & 56.400 \\
\hline 2002 & 268 & 61 & 669 & $(1.321)$ & 8.097 & 268 & 1.328 & 4.949 & $(2.090)$ & 66.600 & 263 & 1.495 & 4.845 & 0,24 & 54.500 \\
\hline 2003 & 264 & 221 & 1.198 & $(1.853)$ & 17.800 & 264 & 1.517 & 5.571 & $(862)$ & 67.800 & 275 & 2.316 & 7.632 & 0,34 & 88.700 \\
\hline 2004 & 268 & 306 & 1.268 & (490) & 17.900 & 268 & 1.716 & 6.231 & $(1.091)$ & 69.900 & 283 & 2.986 & 9.891 & 0,19 & 112.000 \\
\hline 2005 & 262 & 398 & 1.741 & (909) & 23.700 & 262 & 2.033 & 7.364 & $(861)$ & 78.800 & 269 & 4.009 & 14.100 & 0,54 & 171.000 \\
\hline 2006 & 290 & 390 & 1.849 & $(1.063)$ & 25.900 & 290 & 2.179 & 8.237 & $(1.125)$ & 97.500 & 282 & 5.333 & 18.600 & 0,26 & 228.000 \\
\hline 2007 & 306 & 456 & 1.897 & (429) & 21.500 & 307 & 2.480 & 9.178 & (913) & 114.000 & 346 & 6.558 & 29.300 & 4,28 & 430.000 \\
\hline 2008 & 298 & 446 & 2.518 & $(4.213)$ & 33.000 & 298 & 3.170 & 12.000 & $(1.145)$ & 138.000 & 326 & 4.224 & 16.900 & 1,93 & 224.000 \\
\hline 2009 & 293 & 454 & 2.081 & $(1.143)$ & 29.000 & 293 & 3.639 & 13.200 & $(1.337)$ & 159.000 & 330 & 6.977 & 27.200 & 1,87 & 347.000 \\
\hline 2010 & 293 & 680 & 2.995 & (630) & 35.200 & 293 & 4.769 & 20.800 & (1.613) & 307.000 & 324 & 7.801 & 30.300 & 2,25 & 380.000 \\
\hline $1997-2010$ & 3.849 & 282 & 1.617 & $(4.213)$ & 35.200 & 3851 & 2.066 & 9.335 & $(2.635)$ & 307.000 & 4.159 & 3.493 & 16.800 & 0,51 & 430.000 \\
\hline
\end{tabular}

Onde:

LUC = Lucro Líquido;

$\mathrm{PL}=$ Patrimônio Líquido;

DP: desvio-padrão;

$\mathrm{VM}=$ Valor de Mercado;

Min.: mínimo;

Obs.: número de observações;

Máx.: máximo. 
O Gráfico 1, a seguir, apresenta a evolução das médias anuais de cada uma das três variáveis do trabalho:

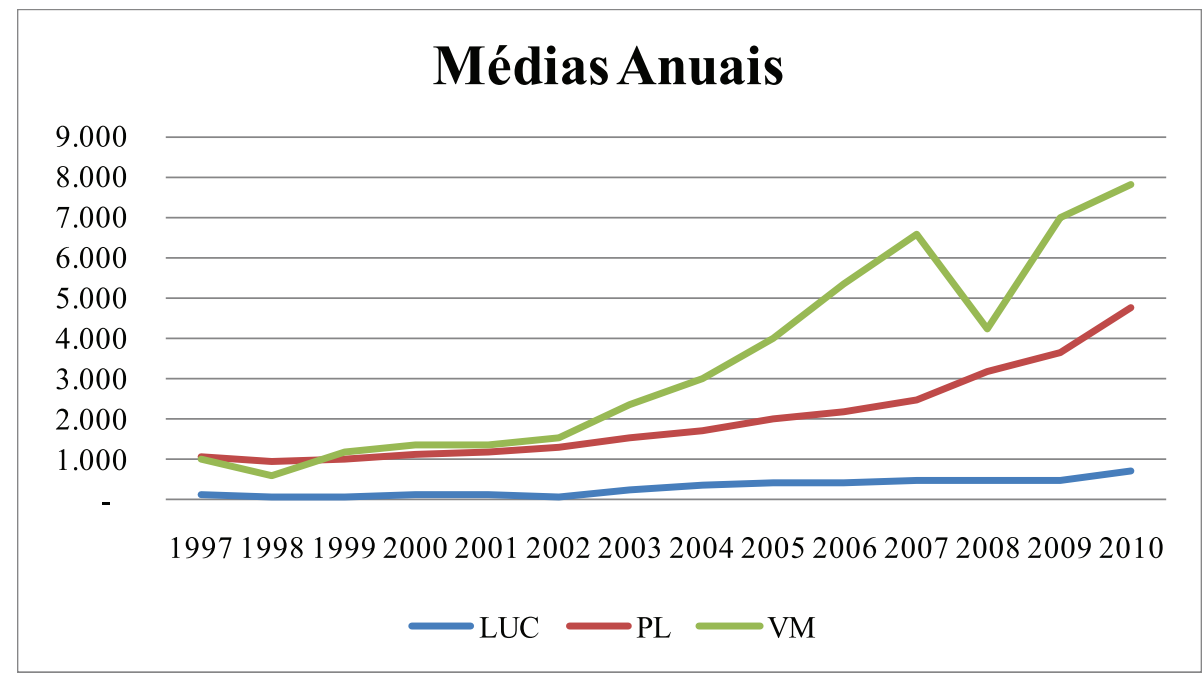

No período em questão, as companhias pesquisadas apresentam geralmente aumento consecutivo de lucro líquido e patrimônio líquido. Há exceções, como os anos de 1999 e 2002, nos quais o lucro líquido é menor em média do que o ano anterior. Já para o patrimônio líquido, com exceção de 1998, ele aumenta de maneira contínua. Um fator a ser destacado é o aumento significativo do desvio-padrão das variáveis ao longo dos anos.

Em contraponto aos aumentos contínuos do patrimônio líquido e do lucro líquido (considerando as exceções), o valor de mercado médio sofre reduções significativas em 1998 e 2008, anos de crise macroeconômica. A exceção é o ano de 2002, cujo valor médio continuou aumentando em relação ao ano anterior.

\section{RESULTADOS}

Para avaliar se a relevância da informação contábil é afetada em períodos de crises macroeconômicas, a equação 2 foi utilizada. Os coeficientes dos efeitos fixos de cada empresa e cada ano não foram apresentados visando uma apresentação mais concisa dos resultados (Tabela 2).

Tabela 2: Regressão do valor de mercado da empresa em função do patrimônio líquido e lucro, sob o efeito de crises econômicas (1997 a 2010) - duplo efeito fixo

\begin{tabular}{c|c|c|c|c|c|c|c|c}
\hline \multicolumn{8}{c}{$\mathrm{VM}_{\mathrm{it}}=\beta_{0}+\beta_{\mathrm{i}}+\beta_{\mathrm{j}}+\beta_{1} \mathrm{CR}_{\mathrm{i}}+\beta_{2} \mathrm{PL}_{\mathrm{it}}+\beta_{3} \mathrm{CR} \times \mathrm{PL}_{\mathrm{it}}+\beta_{4} \mathrm{LUC}_{\mathrm{it}}+\beta_{5} \mathrm{CR}_{\mathrm{LUC}} \mathrm{LUt}_{\mathrm{it}}+\varepsilon_{\mathrm{it}}$} \\
\hline & $\boldsymbol{\beta}_{\mathbf{0}}$ & $\boldsymbol{\beta}_{\mathbf{1}}$ & $\boldsymbol{\beta}_{\mathbf{2}}$ & $\boldsymbol{\beta}_{\mathbf{3}}$ & $\boldsymbol{\beta}_{\mathbf{4}}$ & $\boldsymbol{\beta}_{\mathbf{5}}$ & $\mathrm{R}^{2}$ Ajustado & Observações \\
\hline Coeficiente & $\mathbf{0 , 8 3}$ & $\mathbf{- 0 , 2 6}$ & $\mathbf{0 , 2 5}$ & $\mathbf{0 , 0 9}$ & $\mathbf{2 , 1 3}$ & $\mathbf{- 0 , 6 7}$ & 0,27 & 1.904 \\
\hline estatística t & 18,30 & $-4,00$ & 8,80 & 2,50 & 12,70 & $-2,60$ & & \\
\hline p-value & 0,00 & 0,00 & 0,00 & 0,01 & 0,00 & 0,01 & & \\
\hline erro-padrão & 0,05 & 0,06 & 0,03 & 0,03 & 0,17 & 0,26 & Prob $>\mathrm{F}$ & 0,00 \\
\hline
\end{tabular}

\section{Onde:}

$\mathrm{CR}_{\mathrm{i}}=$ variável dummy, que assume 0 para o período sem crise, e 1, para os anos de crise: 1997, 1998, 1999, 2002, 2007 e 2008;

$\mathrm{VM}_{\mathrm{ij}}=$ Valor de mercado da empresa $\mathrm{i}$ em 30 de abril no ano $\mathrm{t}+1$;

$\mathrm{PL}_{\mathrm{ij}}{ }^{\mathrm{ij}}=$ Patrimônio líquido da empresa i no ano t;

$\mathrm{LUC}_{\mathrm{ij}}=$ Lucro líquido da empresa i no ano t. 
A análise da Tabela 2 indica que as crises financeiras brasileiras (1997, 1998, 1999, 2002, 2007 e 2008) impactam a relevância da informação contábil, tanto em relação ao patrimônio líquido quanto em relação ao lucro líquido ${ }^{2}$. O coeficiente e o $p$-value da Dummy, $\beta_{1}$, demonstra o efeito no ano de crise (conforme a expectativa).

Os valores observados dos coeficientes do patrimônio líquido ( $\beta 2)$ e do lucro ( $\beta 4)$ apresentaram comportamento positivo para os intervalos estudados, permitindo inferir que o patrimônio e o lucro são relevantes, capturando parte da realidade econômica da empresa. Os resultados confirmam o que foi observado por meio do modelo proposto por Ohlson (1995). Assim, a condição estudada da crise contribui para a literatura sobre relevância no Brasil (LOPES: 2001; COSTA: 2005), demonstrando que tanto o patrimônio líquido quanto o resultado do período são relevantes. Os resultados observados para os coeficientes do patrimônio líquido $\left(\beta_{2}=0,25\right)$ e do lucro $\left(\beta_{4}=2,13\right)$ atendem, portanto, à expectativa teórica.

Os resultados encontrados para os coeficientes do patrimônio líquido e do lucro são diferentes dos encontrados por Lopes (2001) e Costa (2005). Após o tratamento de outliers e a utilização de dados em painel com efeito fixo para as companhias da amostra, nota-se que o coeficiente e a significância do lucro líquido (estatística t) não são inferiores aos do patrimônio líquido. Os resultados também podem estar relacionados à metodologia de tratamento dos dados, além da alteração do modelo contábil brasileiro a partir de 2007 e seu maior distanciamento do resultado para fins fiscais após a introdução do Regime Tributário de Transição.

O impacto das crises financeiras pode ser avaliado pelos coeficientes estatisticamente significativos de $\beta_{3}$ ( $p$-value $\left.=0,01\right)$ e $\beta_{5}$ ( $p$-value $\left.=0,01\right)$. Os resultados corroboram a expectativa dos estudos realizados em outros países (GRAHAM e KING, 2000; HO et al., 2001; DAVIS-FRIDAY et al., 2006; DAVIS-FRIDAY e GORDON, 2005). A relevância do patrimônio líquido aumenta ( $\beta_{3}$ é positivo) e a do lucro líquido diminui ( $\beta 5$ é negativo) em anos de crise. Assim, os resultados confirmam a hipótese H1 deste trabalho.

\section{CONCLUSÕES E SUGESTÕES}

Esta pesquisa teve por objetivo verificar se as crises brasileiras de 1997, 1998, 1999, 2002, 2007 e 2008 afetaram a relevância da informação contábil das empresas brasileiras. Especificamente, pretendeu-se verificar se a relevância do patrimônio líquido das empresas brasileiras aumentou enquanto a do lucro diminuiu com as crises econômicas. Tais expectativas foram confirmadas, ratificando a hipótese H1 desenvolvida neste trabalho.

As evidências apontam que a utilidade do lucro líquido para projeções de fluxos de caixa futuros é reduzida devido à instabilidade da economia. Já o patrimônio líquido poderia ser tratado como uma opção de abandono em períodos de crise. Outro fator que também pode contribuir para os resultados é o grau de conservadorismo contábil. Assim, os fatores macroeconômicos também devem ser levados em consideração nas análises de relevância.

Torna-se interessante o desenvolvimento de novas pesquisas que considerem outros aspectos, como os mecanismos de governança corporativa e também o efeito na liquidez das ações tanto no período de desaceleração quanto no de retomada do crescimento. Muitas pesquisas são focadas na relação entre variáveis contábeis e de mercado, e as oscilações extremas nestas últimas podem afetar as conclusões e as análises. Assim, especificações que mitiguem tais efeitos, como a implementação de modelos que utilizem somente variáveis contábeis ou até não financeiras, podem auxiliar na compreensão da utilidade da Contabilidade para a tomada de decisão.

Por fim, a pesquisa pode ser expandida ao considerar uma amostra de países latino-americanos. A relevância da informação contábil pode ser afetada porque não só os ambientes institucionais são diferentes, como também as políticas empregadas para mitigar os efeitos da crise são específicas de cada jurisdição.

2 Regressões com especificações diferentes, como a exclusão de companhias com patrimônio líquido negativo e/ou resultado líquido negativo apresentam resultados qualitativamente similares (significância estatística e sinais dos coeficientes). 


\section{REFERÊNCIAS}

AMIR, Eli; LEV,Baruch. Value-relevance of nonfinancial information: the wirelles communication industry. Journal of Accounting \& Economics, v.22, 1996. pag 3-30

ARAÚJO, Carlos Hamilton Vasconcelos; GUILLÉN, Osmani Teixeira de Carvalho de. Componentes de curto e longo prazo das taxas de juros no Brasil. Banco Central do Brasil, Trabalhos para Discussão, no 55, Brasília, DF, 2002. Disponível em: <http://www.bacen.gov.br > . Acesso em 01/11/2011.

BAER, Werner. A economia brasileira. 2. ed. São Paulo: Nobel, 2002.

BALL, R.; KOTHARI, S. P.; ROBIN, A. The effect of international institutional factors on properties of accounting earnings. Journal of Accounting and Economics, v. 30, 2000.

BARTH, Mary E. Valuation-based accounting research: implications for financial reporting and opportunities for future research. Accounting and Finance, v. 40, 2000. pag 7-31

BARTH, Mary E.; BEAVER, W.; LANDSMAN, W. Relative valuation roles of equity book value and net income as a function of financial health. Journal of Accounting and Economics, v. 25, 1998. pag 1-34

BARTH, Mary E.; BEAVER, William H.; LANDSMAN, Wayne R. The Relevance of the value relevance literature for financial accounting standard setting: another view. Journal of Accounting and Economics, v. 31, 2001. p. 77-104

BASU, S. The conservatism principle and the asymmetric timeliness of earnings. Journal of Accounting and Econimics, v. 24, 1997. p. 3-37

CARDOSO, Eliana; HELWEGE, Ann. Currency crises in the 1990s: the case of Brazil. NBER Conference of Brazilian's Crises. Jun. 1999.

CARDOSO, R. L.; MARTINS, V. A. Hipótese de mercado eficiente e modelo de precificação de ativos financeiros. In: IUDÍCIBUS, Sérgio de; LOPES, Alexsandro Broedel. Teoria avançada da contabilidade. São Paulo: Atlas, 2004.

COLLINS, Daniel W; PINCUS, Morton; XIE, Hong. Equity valuation and negative earnings: the role of book value of equity. The Accounting Review, v. 74, n. 1, 1999. p. 29-61

COSTA, Fábio M.. Ajustes aos US-GAAP: estudo empírico sobre sua relevância para empresas brasileiras com adrs negociados na bolsa de Nova Iorque. 2005. Tese (Doutorado em Controladoria e Contabilidade) - Departamento de Contabilidade e Atuária, Faculdade de Economia, Administração e Contabilidade, Universidade de São Paulo, São Paulo.

COSTA, Fábio M.; LOPES, Alexsandro B.; COSTA, Alessandra Cristina de O. Conservadorismo em cinco países da América do Sul. Revista de Contabilidade e Finanças, São Paulo, n. 41, p. 7-20, Maio/ Ago, 2006.

CROUHY, Michale G.; JARROW, Robert A. e TURNBULL, Stuard M. The Subprime Credit Crisis of 07. Working paper. Cornell Univesity. 2008. 
DAVIS-FRIDAY, Paquita Y.; GORDON, Elizabeth A. Relative valuation roles of equity book value, net income, and cash flows during a macroeconomic shock: the case of Mexico and the 1994 currency crisis. Journal of International Accounting Research, v. 4, n. 1, 2005. p. 1-21

DAVIS-FRIDAY, Paquita Y.; ENG, Li Li; LIU, Chao-Shin. The effects of the Asian crisis, corporate governance and accounting system on the valuation of book value and earnings. International Journal of Accounting, v. 41, 2006. p. 22-40

DYCKMAN, T. R. The effects of restating financial statements for price-level changes: A comment. The Accounting Review, v. 50, n. 4, 1975. p. 796-808

FELTHAM, G.; OHLSON, J. Valuation and clear surplus accounting for operating and financial activities. Contemporary Accounting Research, v.11, n. 2, 1995. p. 689-731

FILGUEIRAS, L. A. M.. História do plano real: fundamentos, impactos e contradições. São Paulo: Bomtempo, 2003.

GRAHAM, R. C.; KING, R. D. Accounting practices and the market valuation of accounting numbers: evidence from Indonesia, Korea, Malaysia, the Philippines, Taiwan, and Thailand. The International Journal of Accounting, v.35, n.4, Oct., 2000. p. 445-470

GREMAUD, A. P.; VASCONCELLOS, M. A. S. de; TONETO JÚNIOR, R.. Economia brasileira contemporânea. 5 ed.São Paulo: Atlas, 2004.

HENDRIKSEN, E. S.; BREDA, M. F. V.. Teoria da contabilidade. São Paulo, Atlas, 1999.

HO, L-C.; LIU, C-S; SOHN, P. The value relevance of accounting information around the 1997 Asian financial crisis: the case of South Korea. Asia-Pacific Journal of Accounting and Economics, v. 8, 2001.p. 83-107

HOLTHAUSEN, R. W.; WATTS, R. L. The relevance of the value-relevance literature for financial accounting standard setting. Journal of Accounting and Economics, v. 31, 2001. p. 9-75

LANZANA, A. E. T.. Economia brasileira: fundamentos e atualidade. São Paulo: Atlas, 2001.

LOPES, A. B.. Uma Contribuição ao estudo da relevância da informação contábil para o mercado de capitais: o modelo de Ohlson aplicado à BOVESPA. 2001. Tese (Doutorado em Controladoria e Contabilidade) - Departamento de Contabilidade e Atuária, Faculdade de Economia, Administração e Contabilidade, Universidade de São Paulo, São Paulo.

LOPES, A. B.; MARTINS, Eliseu. Teoria da Contabilidade: uma nova abordagem. São Paulo: Atlas, 2005.

LOPES, A. B.; WALKER, M. Asset revaluations, future firm performance and firm-level corporate governance arrangements: new evidence from Brazil? The British Accounting Review, v. 44, n. 2, jun. 2012. p. 1-15 2011.

MEEK, Gary K., THOMAS, Wayne B. A review of markets-based international accouting research. Journal of International Accounting Research, v.3, 2004. p. 21-41. 
MIRANDA, Mauro Costa. Crises cambiais e ataques especulativos no Brasil. Banco Central do Brasil, Textos para Discussão, 1999.

MURTA, L. R.; BRASIL, G. H.; SAMOHYL, R. W. Crise monetária brasileira de 1999: uma análise econométrica realizada com base em elementos teóricos de modelos de crises monetárias de primeira e segunda geração. ANPEC, 2003. Disponível em: http://www.anpec.org.br. Acesso em 25/11/2011.

MYERS, James. Implementing residual income valuation with linear information dynamics. The Accounting Review, v. 74, n 1, 1999. p. 1-28

OHLSON, J. Earnings, book value, and dividends in equity valuation. Contemporary Accounting Research, v. 11, n 2, 1995. p. 661-687

OHLSON, J. A.; JUETTNER-NAUROTH, Beate. Expected EPS and EPS growth as determinants of value. Review of Accounting Studies, v.10, 2005. p. 349-365

YU, S. C. Microaccounting and macroaccounting. The Accounting Review, v. 41, n 1, Jan., 1966. p. 8-20 